\title{
Improved Collecting Line Current Protection Scheme against Large-scale Wind Generators Tripping off
}

\author{
Wei Jin ${ }^{1, *}$, Yuping Lu ${ }^{1}$, Senior Member, IEEE and Tao Huang ${ }^{2}$ \\ 1 School of Electrical Engineering, Southeast University, Nanjing, 210096 China \\ Jinwei86837871@,outlook.com (W. J.); luyuping@seu.edu.cn (Y.P. L.) \\ 2 R \& D Department, NR Electric CO., LTD., Nanjing, 211102 China \\ * Correspondence: jinwei86837871@outlook.com; Tel.: +86-13407534203
}

\begin{abstract}
There have been several cases of large-scale wind generators (WGs) tripping off caused by untimely fault removing in recent years. Currently, the discoordination between the box-type transformer fuse protection (BTFP) and two-section collecting line current protection (CLCP) brings a security risk to wind farm. In order to ensure the selectivity, the first section (Sec-I) CLCP should be set a enough interval that is longer than the fuse melting time, and another interval is set for the Sec-II CLCP, which weakens the speed of the CLCP. When a fault occurs on the collecting line, there is no doubt that WGs cannot work too long in abnormal operation, which may cause WGs to be placed off the grid. For a power system with high penetration of wind power, large-scale WGs tripping off will cause a great power shortage, and affect the stability of the power system. The selectivity and sensitivity of the CLCP is analyzed in detail to make the CLCP speed better. Considering the fault ride-through ability of WGs, the fault clear time is an important factor to lead to large-scale WGs tripping off. Two main works are done in this paper. The first is to accelerate the speed of the Sec-I CLCP though reducing the protection zone. Another one is introduce the risk assessment module into the CLCP, which not only improve the speed of the CLCP but also ensure the safety of the wind farm during faults. According to the deference in trip-off causes of WGs, the matching functions are created to assess the trip-off risk of WGs on the spot. In the case of fault, the trip-off risk indicators of WGs are timely updated to data sharing center and open to the CLCPs. The set of risk indicators is divided into several subsets according to the risk range. The dynamic changes of the subsets during fault help to improved CLCP scheme. This scheme can accelerate protection speed based on the increasing risk of large-scale WGs tripping off in wind farms. Compared with traditional CLCP, this approach can make the CLCP combines selectivity and speed better based on the analysis of the ride- through ability of WGs.
\end{abstract}

Keywords: Collecting line current protection (CLPC); coordination protection; large-scale WGs trip-off; risk indicator

\section{Introduction}

LARGE-scale grid-connected wind power is of great significance to ease energy shortage and promote the development of green energy [1]-[4]. With the continuous increasing permeability of wind power, the security problems it brings cannot be ignored. Large-scale WGs tripping off during faults has brought serious impacts on power system and exacerbated accidents in recent years [5]-[10]. Wind power, which is more and more important for the power system in future, should play a supporting role in the power grid. However, it consequently aggravates the accident in some case [11]-[21]. Therefore, these issues are attracting the attention of an increasing number of scholars.

In wind farms, collecting lines, as an indispensable part for the transmission of wind energy, are the connection hub between wind generators and transmission lines. It is very serious but common that a fault happens on collecting line. There have been several cases reported since 2011 in China [7]-[9]. Unfortunately, in some cases of collecting line faults, large-scale WGs trip off the grid, which has serious impacts on the power system in the end. The action delay and non-selectivity of the CLCP exacerbates these accidents to a certain extent. In fact, the contradiction between sensitivity and selectivity of the CLCP remains unsolved [5]-[15]. Adaptive setting methods of the CLCP are proposed in [5]-[11]. By estimating injection current of WGs and considering low-voltage-ride-through strategies of WGs, the current setting values are adjusted in real time. However, it is difficult to accomplish the goal because of the various operation conditions of WGs. For any fault, it may be unique considering the fault location, fault type and the status of WGs, etc. Consequently, Self-adjusting setting method is not a good solution. Drawing lessons from traditional line protection, differential protections are proposed in [12]-[15]. However, the high-voltage side of the box-type transformer is only equipped with fuse element. In order to achieve differential protection, both the terminals of collecting line should be equipped with protective relay and circuit breaker. There is no doubt that the construction for wind farms in the cost will increase with the increasing number of WGs. The best way is to find a proper method without adding equipment. 
The non-selective action and delay action of the CLCP may lead to large-scale WGs tripping off. Some current studies focus on predicting the risk of WGs tripping off During faults [16]-[21]. Drawing lessons from the traditional off-line calculation methods, the system models, data in normal operation conditions and the hypothetical faults are used to study these issues by off-line simulation and calculation. When the actual fault happens, whether WGs trip off or not will be judged according to the previous simulation. Obviously, if the actual fault is the same as the hypothetical fault, the statuses of WGs are immediately known after fault. The key issue is that we cannot exhaustively troubleshoot all conditions. In addition, inaccurate equivalent models for WGs may also show a large deviation. Furthermore, the off-line calculation methods only focus on the line voltage sags in wind farm, which makes it still not comprehensive enough. In practice, there is a variety of reasons for large-scale WGs tripping off during faults.

The fault duration time and fault ride through ability are found to be very important reasons for large-scale WGs tripping off [22]-[25]. Fuses are economical in the cost to protect box-type transformers and used at present in great numbers in wind farms. To ensure selectivity, the interval between the zone-I CLCP and BTFP is necessary. However, when a fault occurs on the collecting line, it will weaken the speed of CLCP and take a longer time for CLCP to remove the fault. The risk of WGs tripping off is related to the fault duration. To improve the speed, the Sec-I CLCP protects part length instead of the full length of collecting line. Furthermore, the Sec-II CLCP makes full use of the WGs statues in wind farm to speed better. The WGs tripping off causes are divided into three types according to the difference in protective relays in this paper. Mathematical models are used to classify and quantify the risk of WGs tripping off. After the possibility of WGs tripping off is calculated, the dynamic classification analysis method is used to evaluate the risk of large-scale WGs tripping off in wind farms. The risk assessment module is introduced into the CLCP logic to help it speed better when the risk of large-scale WGs tripping off is high. The setting time of improved CLCP is adaptive and varies with the increasing number of WGs going off grid. The Sec-II CLCP is not only the back-up protection of the BTFP and the Sec-I CLCP, but also the back-up protection of the wind farm, which increases the safety of wind farm.

\section{Analysis of the CLCP}

Fig. 1 shows a typical electric construction diagram in wind farm. It is a 35KV neutral ungrounded system [7] [26]. The current CLCP in wind farm adopts conventional feeder protection scheme. Because the collecting lines are already at the end of power system, the CLCP is simplified from three-section feeder protection to two-section protection. The setting principle is as follows. The first section protects the full collecting line with delay time $t_{1}$ and the second one is taken as the back-up protection with delay time $t_{2}$. The fuse element protects the box-type transformer. The action time of the two-section CLCP should be in coordination with the fuse melting time to achieve selectivity.

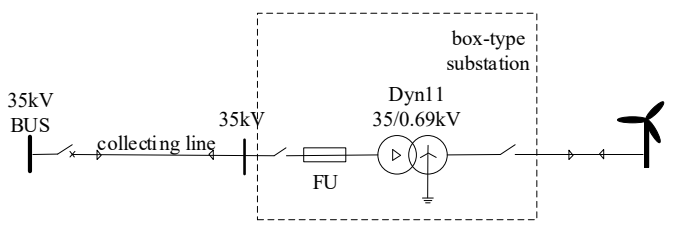

Figure 1. Typical diagram of collecting line to wind generator in wind farm

\subsection{Sensitivity analysis of the CLCP}

The setting current $\left(I_{\text {set }}^{I}\right)$ of the first section protection is set according to phase-phase short-circuit $\left(I_{k \cdot \min }^{(2)}\right)$ at the end of the collecting line in the minimum operating mode. The pickup current of the second section $\left(I_{\text {set }}^{I I}\right)$ is set according to the maximum load current ( $I_{L d \text {.max }}$ ) of the collecting line. It is obvious that the second protection is more sensitive than the first. However, considering the current provided by the wind generators and the reliability coefficient, the first section protection zone will extend to the box-type transformer. When the box-type transformer faults, the short-circuit current can also make the first section protection pick up. The settings are usually according to the following principle [26].

$$
\left\{\begin{array}{l}
I_{\text {set }}^{I}=K_{r e l}^{I} I_{k \cdot \text { min }}^{(2)} \\
I_{\text {set }}^{I I}=K_{r e l}^{I I} I_{L d \cdot \max }
\end{array}\right.
$$

Where $K_{r e l}^{I}$ and $K_{r e l}^{I I}$ are the reliability coefficients. $K_{r e l}^{I}$ is generally in the range $[0.75,0.85]$ and $K_{r e l}^{I I}$ is generally in the range $[1.2,1.3]$. 


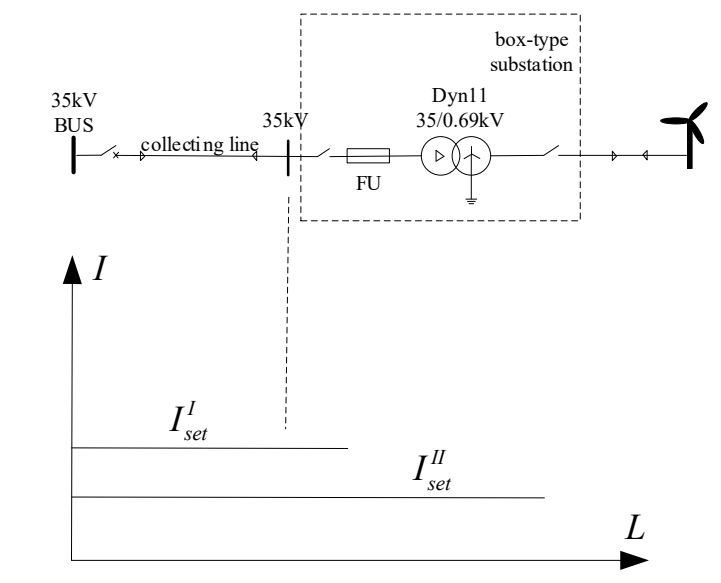

Figure 2. Typical settings of the CLCP and its protection zone

The short-circuit current provided by WGs varies widely and plays a crucial role in the sensitivity of CLCP. Of course, it is inseparable from the low-voltage-ride-through (LVRT) strategies. For high-permeability wind power or large-scale wind farms, the influence of wind generators cannot be ignored.

\subsection{Selectivity analysis of the CLCP}

The setting time $\left(t_{\text {set }}^{I}\right)$ of the first section protection should be in coordination with the fuse melting time. When the box-type transformer and wind generators fault, the fuse protection picks up and removes the fault. The CLCP should be able to return reliably to avoid over-level tripping. In order to ensure the coordination of CLCP and BTFP, the time coordination relationship is as follows:

$$
\left\{\begin{array}{l}
t_{\text {set }}^{I}=t_{M}+\Delta t \\
t_{\text {set }}^{I I}=t_{\text {set }}^{I}+\Delta t
\end{array}\right.
$$

Where $\Delta t$ is the interval of the protection coordination and generally in the range [0.2s, $0.5 \mathrm{~s}]$.

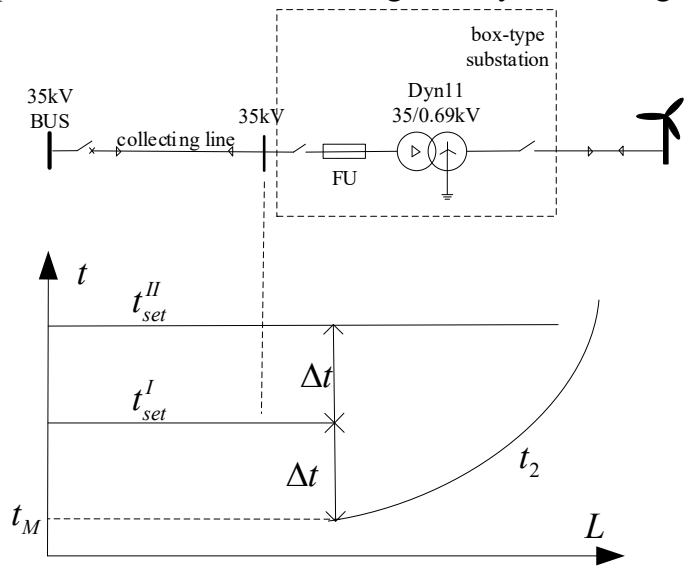

Fig.3 Typical time coordination between the CLCP and the BTFP

The melting time $\left(t_{2}\right)$ is related to the fault current flowing through. Wind generators provide part of the fault current. If the total power of the WGs is large enough, $t_{2}$ will vary greatly and thus it may lead to non-selectivity between CLCP and BTFP. In most instances, we increase the coordination time to avoid this problem. Consequently, the fault cannot be removed rapidly when the fault occurs on collecting lines, which may aggravate the accident in some cases.

\subsection{Influence of the CLCP on wind farm}

Similar to conventional over-current protection, the CLCP should be in coordination with lower-level protection. As is known, the control system of WGs consists of power electronic devices. Power electronic devices are extremely sensitive to operating voltage sags and operating current change, which makes them susceptible to voltage and current breakdown. When 
the system voltage and current fluctuates widely, the protective relays of WGs will make them tripping off the grid. Therefore, large-scale WGs will be off-grid in some conditions. Fault duration time is the key factor which leads to WGs tripping off. Minimizing operating times of the CLCP and satisfying selectivity constraints are very important work we should do. If we only focus on the characteristics of the CLCP itself and ignore the adaptability of WGs in wind farms, it is impossible to prevent the case of large-scale WGs tripping off. This is what we should also focus on,

\section{Improved CLCP scheme against large-scale WGs tripping off}

\subsection{Speed improvement of the CLCP}

According to the analysis above, the coordination between the first section of CLCP and BTFP is achieved by adding delay time. When the selectivity of the CLCP guaranteed, the speed of the CLCP is weakened. This is a compromise scheme. Therefore, we improve the CLCP in the following ways. 1) Increasing the setting current and reducing the delay time of the first section of the CLCP. The setting current $\left(I_{s e t}^{I}\right)$ of the first section protection is set to ensure sensitivity when phase-phase short circuit at the end of collecting line in the maximum operating mode. 2) Changing the second section time interval from the definite time to variable time. The setting current of the second section remain unchanged as before. If the WGs are in good working conditions, the protective relay will not trip the circuit breaker until the definite time is reached. Otherwise, if the large-scale WGs are in the risk of tripping off assessed by risk indicators, the protective relays will trip the circuit breaker even though the definite time is unreached. The analysis is in the next section in detail.

$$
\left\{\begin{array}{l}
I_{\text {set }}^{I}=K_{r e l}^{I} I_{k \cdot \min }^{(2)} \\
I_{\text {set }}^{I I}=K_{r e l}^{I I} I_{L d \cdot \max }
\end{array}\right.
$$

Where $K_{r e l}^{I}$ and $K_{r e l}^{I I}$ are the reliability coefficients. $K_{r e l}^{I}$ is in the range from $[1.2,1.5]$. As is shown, we reduce the protection zone to ensure selectivity in the same time.

$$
\left\{\begin{array}{l}
t_{\text {set }}^{I}=\Delta t_{1} \\
t_{\text {set }}^{I I}=\min \left\{\Delta t_{2}, \Delta t_{\text {risk }}\right\}
\end{array}\right.
$$

Where $\Delta t_{1}$ is the time setting of the first section protection. $\Delta t_{1}$ does not need to be in coordination with the fuse melting time. $\Delta t_{2}$ is the definite time of the protection coordination and generally in the range $[0.5 \mathrm{~s}, 1 \mathrm{~s}], \Delta t_{\text {risk }}$ the variable time and related to the time of WGs tripping off risk over the settings.

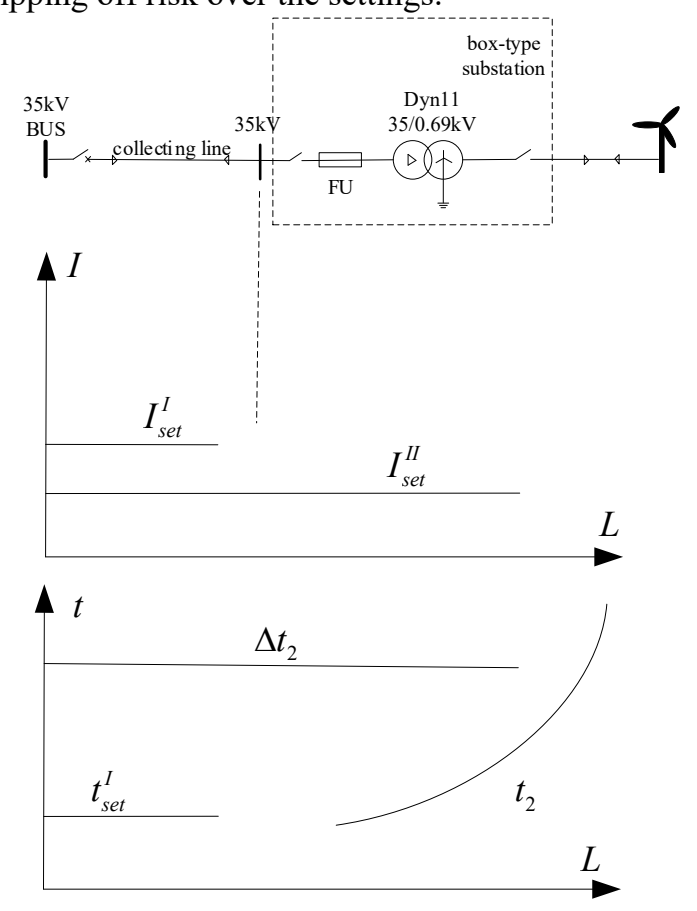

Figure 4. The settings relationship and coordination between the CLCP and the BTFP 


\subsection{Risk Indicators of WGs tripping off}

We define the risk indicator, represented by $\gamma$, to assess the probability of WG tripping off in the next period. The range of risk indicator is $[0,100 \%]$. The larger the value is, the greater the possibility of WGs tripping off will be.

WGs have limited ability to ride through faults. In order to ensure safety, WGs are usually equipped with voltage protection, current protection, frequency protection, etc. These WGs will go off the grid with any protection action. As different protective relays have different characteristics, we need to perform classification analysis on the protective relays.

The possibility of WGs tripping off depends on the margin between signal measurement and the protection settings. The essential conditions for protection action is the measurement beyond the setting value as well as reaching the setting time. To calculate the risk indicator, we should establish a corresponding relationship between the protection margin and the risk indicator. Considering the differences in protective relays, we divided the possible causes of WG tripping off into three types.

3.2.1 Type X: protective relays equipped with short time threshold, such as instantaneous trip current protection.

Considering communication delay, we classify protective relays with the setting time less than $0.08 \mathrm{~s}$. For the protective relays of type $\mathrm{X}$, we are mainly concerned with the margin between the setting value and the signal measurement.

Taking overvoltage protection for example, the greater the voltage deviates from the rated value, the higher WGs overvoltage risk is. When the measured voltage beyond the setting voltage, these WGs cannot keep connecting to the grid. Therefore, the risk indicator is $100 \%$ at this time. When the measured voltage is close to the rated voltage, these WG are in normal operation conditions and the risk indicator is close to $0 \%$ at this time. Even though it is a monotonically increasing function between the risk indicator and the measured voltage value, it is not linear. With the increasing of the measured voltage, the changing process of the risk indicator is as follows. The risk indicator is related to the safe margin, which is the difference between the setting value and the measurement. Base on the analysis above, we create an approximate fitting function.

The relationship between the risk indicator and the safe margin is as follows.

$$
\gamma(X)=\left(\frac{x-x_{N}}{x_{\text {set }}-x_{N}}\right)^{k}
$$

where $x, x_{N}$ and $x_{\text {set }}$ are the measured value, the rated value and the setting value, $k$ the adjustment coefficients, $\gamma(X)$ the risk indicator of WGs tripping off.

In (5), $k$ is generally in the range $[0,1]$ to achieve the desired effect. It is more reasonable when $k$ is equal to 0.3 through multiple calculations. The value of $k$ is 0.3 in this paper.
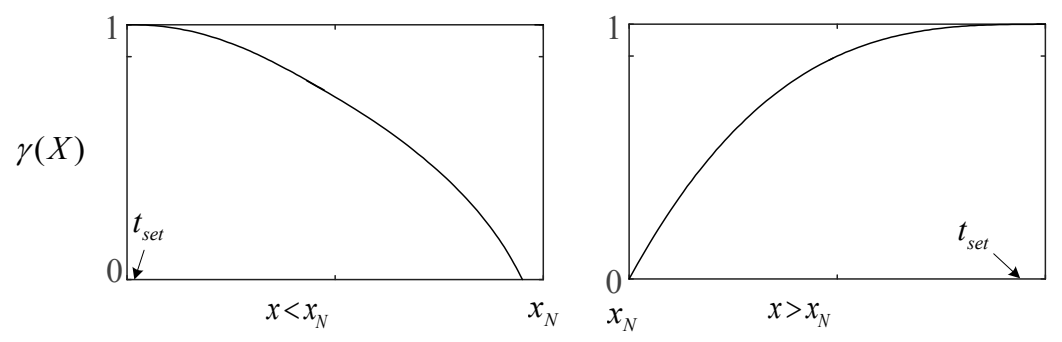

Figure 5. Quantitative relationship between the risk indicator and the measured value in type $\mathrm{X}$

From fig. 5(a) (b), the closer $x$ is to $x_{\text {set, }}$, the greater the value of $\gamma(X)$ is. $\gamma(X)$ increases rapidly with $x$ over/under the rated value. In this case, the possibility of WGs tripping off increases. The information is shared to the CLCPs and further measures should be taken in time.

\subsubsection{Type Y: protective relays equipped with long time threshold, such as the frequency protection.}

Taking frequency protection for example, when the frequency reaching the pickup value and time threshold, the WGs may go off the grid. Therefore, the risk indicator is $100 \%$ at this time. When the pickup values are satisfied, the fault duration time is the key factor that affects the WGs tripping off. Obviously, the risk indicator increases with fault time. Base on the analysis above, we create an approximate fitting function. Considering time margin of protective relays, the relationship between the risk indicator and the time margin is as follows.

$$
\gamma(Y)=1-\left(1-\frac{t}{t_{\text {set }}}\right)^{k}
$$


where $t, t_{\text {set }}$ and $k$ are the fault duration time, the setting time and the adjustment coefficient, respectively.

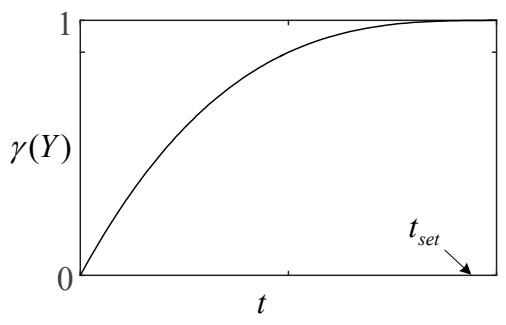

Fig. 6. Quantitative relationship between the risk indicator and the measured value of type Y

For type $\mathrm{Y}$, the first condition to be satisfied is that the measured value $(y)$ is greater than the pickup value $\left(y_{\text {set }}\right)$. We should set up a reasonable $k$ value based on the severity of a fault. Generally, $k$ is in the range $[1,3]$ to achieve the desired effect. We determine the $\mathrm{k}$ value according to the following principles (suppose $t_{\text {set }}=f\left(\mathrm{y}, \mathrm{y}_{\text {set }}\right)$ ). If the setting time is independent of measured value and setting value, $k$ is equal to 1 . If the setting time is related to the measured value, $k$ is equal to 3 . Otherwise, $k$ is equal to 2 .

3.2.3 Type Z: protective relays equipped with over-limit statistics per unit time, such as harmonic voltage over-limit protection.

If the counts up to the setting value, the protection actions. We can calculate the risk indicator as follows:

$$
\gamma(Z)=\frac{n}{n_{\text {set }}}
$$

where $n$ and $n_{\text {set }}$ are the measured counts and the action threshold in a certain period, respectively.

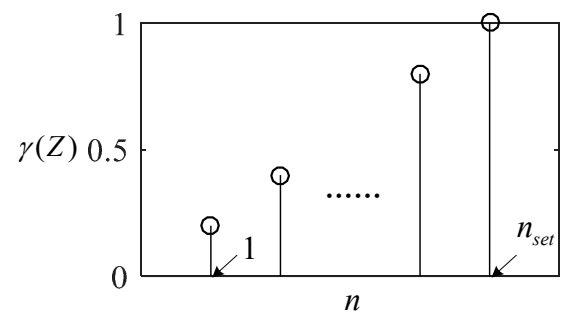

Figure 7. Quantitative relationship between the risk indicator and the measured value of type $Z$

According to the equations (5), (6) and (7) above, we can calculate the risk indicators in real time on the spot. It reflects the rest safety margin of WGs and shows the possibility of the WGs connecting to the grid. Furthermore, we can use this information to improve the CLCP. If properly configured, the CLCP will be smarter and speed better.

\subsection{Quantification of risk indicators}

Any protective relay of the WG can drive the breaker to trip independently. Therefore, the possibility of WG tripping off should be the maximum risk indicators of all the protective relays.

$$
\begin{gathered}
\gamma=\max \left\{\gamma\left(X_{i}\right), \gamma\left(Y_{j}\right), \gamma\left(Z_{k}\right)\right\}, \\
\quad i=1, \mathrm{~L}, m_{1} \\
j=1, \mathrm{~L}, m_{2} \\
k=1, \mathrm{~L}, m_{3}
\end{gathered}
$$

where $\mathrm{i}, \mathrm{j}$ and $\mathrm{k}$ are the numbers of type $\mathrm{X}, \mathrm{Y}$ and $\mathrm{Z}$, respectively.

The risk indicators can be calculated on the spot by the control center of WGs. The information of WGs is shared to Data Sharing Center (DSC) via communications. The CLCPs in wind farm are also connected to the DSC and can get the status information of WGs easily. It avoids the mass data processing and communication delays by distributed computing. At the same time, the CLCPs can improve the effectiveness of the risk assessment for large-scale WGs tripping off. 


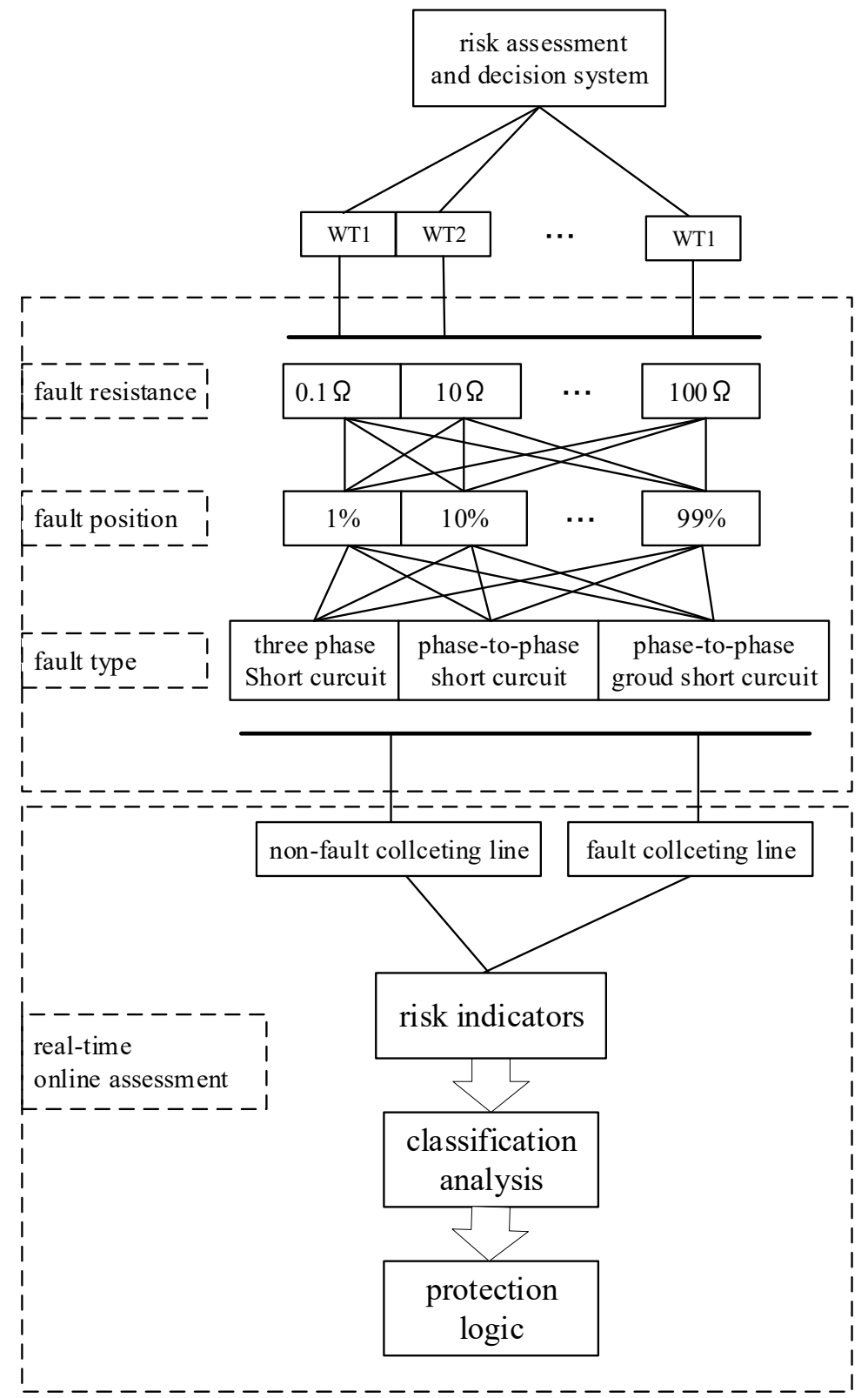

Figure 8. Decision system and evaluation process

As shown in fig. 6, the fault type is generally unknown. In practice, we do not need to care about the fault type. The key is to obtain the risk indicators of the wind farm.

\subsection{Risk assessment of large-scale WGs tripping off}

We divide the risk indicators according to fault line and non-fault line. In order to assess the possibility of WG tripping off, we define several symbols in table I.

TABLE I

SYMBOLS DEFINED

\begin{tabular}{ll}
\hline \multicolumn{1}{c}{ SYMBOLS DEFINED } \\
\hline \hline Symbol & \\
\hline$H_{\mathrm{i}}$ & risk indicator set of WGs \\
$A_{\mathrm{i}}$ & risk indicator set of WGs in the safe zone \\
$B_{\mathrm{i}}$ & risk indicator set of WGs in the transition zone \\
$C_{\mathrm{i}}$ & risk indicator set of WGs in the danger zone \\
$\mathrm{D}_{\mathrm{i}}$ & risk indicator set of WGs in the off-grid zone \\
$P\left(D_{\mathrm{i}}\right)$ & output power of WGs in $D_{\mathrm{i}}$
\end{tabular}


$\operatorname{card}\left(D_{\mathrm{i}}\right) \quad$ number of WGs in $D_{\mathrm{i}}$

$\rho\left(D_{\mathrm{i}}\right) \quad$ percentage of $\operatorname{card}\left(D_{\mathrm{i}}\right) / \operatorname{card}\left(H_{1}\right)$

i subscript $\mathrm{i}=1$, non-fault collecting lines

subscript $\mathrm{i}=2$, fault collecting line

The risk indicators reflect the possibility of WG tripping off. To evaluate the wind farm, the risk indicators are further divided as in (5).

$$
\left\{\begin{array}{l}
A_{i}=\left\{\gamma \mid \gamma<0.6, \gamma \in H_{i}\right\} \\
B_{i}=\left\{\gamma \mid 0.6 \leq \gamma<0.8, \gamma \in H_{i}\right\} \\
C_{i}=\left\{\gamma \mid 0.8 \leq \gamma<0.9, \gamma \in H_{i}\right\} \\
D_{i}=\left\{\gamma \mid \gamma \geq 0.9, \gamma \in H_{i}\right\}
\end{array}\right.
$$

$A, B, C$ and $D$ are four sets of risk indicators belonging to $H$. As shown in fig. 9, if the risk indicators transfer from the $A$ zone to the $D$ zone, the maximum safe fault clear time should decreases in order to avoid large-scale WGs tripping off. This is just a trend and not a linear relationship.

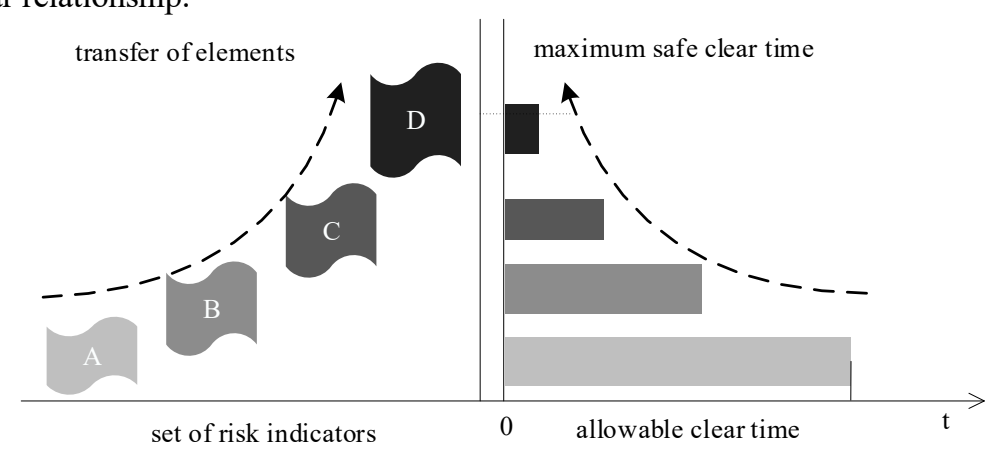

Figure 9. Trend of the maximum safe clear time with change of risk indicators

\subsubsection{Static assessment method}

The main assessment indicators are $P\left(D_{i}\right), \operatorname{card}\left(D_{2}\right)$, and $\rho\left(C_{i}\right)$.

$P\left(D_{j}\right)$ is the total output power of WGs that are likely off-grid on non-fault collecting lines. When $P\left(D_{j}\right)$ is close to $P\left(H_{2}\right)$ (total output power of WGs on the fault line), the CLCP should trip immediately. That is because that the power loss is $P\left(H_{2}\right)$ at this moment. If the fault continues, the WGs on non-fault lines trip off and the power loss will be greater.

$\rho\left(C_{i}\right)$ is the percentage of WGs in the danger zone on non-fault collecting lines. The larger the $\rho\left(C_{i}\right)$ is, the greater the possibility that WGs may be transferred from the $\mathrm{C}$ zone to the $\mathrm{D}$ zone in the next period. It is unfavorable for fault ride-through of WGs in wind farm. When the $\rho\left(C_{j}\right)$ reaches the settings, the protection should promptly isolate the fault.

$\operatorname{card}\left(\mathrm{D}_{2}\right)$ is the number of WGs that are likely to be off-grid on the fault collecting line. When $\operatorname{card}\left(\mathrm{D}_{2}\right)$ is close to $\operatorname{card}\left(\mathrm{H}_{2}\right)$ (number of WGs on the fault collecting line), most of the WGs on the fault collecting line will be automatically off-grid soon. In this case, the protection should action immediately, which can reduce the suffering time of WGs on non-fault collecting lines.

\subsubsection{Dynamic assessment method}

Dynamic assessment is based on the dynamic change of risk indicators in the past period, which helps to identify a potential trend of the wind farm during the fault. We aim to avoid most serious conditions of wind farm so that we can take measures to curb the expansion of the accident in time.

We choose $\rho\left(C_{\mathrm{i}}\right)$ and $\rho\left(A_{\mathrm{j}}\right)$ as the dynamic evaluation parameters. If the current time is $t_{0}$ and the calculation interval is $\Delta t$ , then $\Delta_{1}$ and $\Delta_{2}$ are calculated as follows.

$$
\begin{gathered}
\Delta_{1}=\Delta \rho\left(C_{1}\right)+\Delta \rho\left(D_{1}\right)=\left.\rho\left(C_{1}\right)\right|_{t=t_{0}}+\left.\rho\left(D_{1}\right)\right|_{t=t_{0}}-\left.\rho\left(C_{1}\right)\right|_{t=t_{0}-\Delta t}-\left.\rho\left(D_{1}\right)\right|_{t=t_{0}-\Delta t} \\
\Delta_{2}=\Delta \rho\left(A_{1}\right)=\left.\rho\left(A_{1}\right)\right|_{t=t_{0}}-\left.\rho\left(A_{1}\right)\right|_{t=t_{0}-\Delta t}
\end{gathered}
$$

$\Delta_{1}$ and $\Delta_{2}$ are calculated twice at $t=t_{0}$ and $t=t_{0}+\Delta t$ separately. If $\Delta_{1}>20 \%$ and $\Delta_{2}<-20 \%$, an increasing number of WGs are gradually transferring from the $\mathrm{A}$ zone to the $\mathrm{C}$ and $\mathrm{D}$ zones. In this case, it is considered that the operating status of WGs on non-fault collecting lines is deteriorating rapidly. If the fault is not isolated in time, it is likely to cause large-scale WGs tripping off. If the fault has been isolated, all the risk indicators belong to the set $H_{1}$. If not, further measures should be taken by the emergency control system or regional control system in the wind farm. 


\subsection{Improved CLCP scheme}

Non-selective fault isolation may lead to the removal of the entire collecting line, even though the fault occurs on a single WG branch. If we guarantee the selectivity strictly with the delay time interval, large-scale WGs on the non-fault collecting line may be in the risk of tripping off. Both cases will cause the expansion of the accident.

The priority is to ensure the selectivity. The first section of the CLCP protects the collecting lines from serious fault immediately. The second section, as the backup protection, is not only to remove the faults, but also to prevent large-scale WGs tripping off. Therefore, we avoid large-scale WGs tripping by assessing the risk indicators of wind farm on-line and by monitoring the operating state of WGs on non-fault collecting lines. According to the analysis above, when any of the parameters $P\left(D_{i}\right), \operatorname{card}\left(D_{2}\right), \rho\left(C_{i}\right), \Delta_{1}$ and $\Delta_{2}$ exceed the setting value, the whole fault collecting line should be isolated in time to prevent more WGs going off-grid.

$$
\begin{aligned}
& P\left(D_{1}\right)>0.8 P\left(H_{2}\right) \\
& \rho\left(C_{1}\right)>90 \% \\
& \operatorname{card}\left(D_{2}\right)>0.8 \operatorname{card}\left(H_{2}\right) \\
& \left\{\begin{array}{l}
\Delta_{1}>20 \% \\
\Delta_{2}<-20 \%
\end{array}\right.
\end{aligned}
$$

Fig. 9 shows the logic of CLCP scheme against large-scale WGs tripping off.

The first part is the traditional CLCP. The setting value of Sec-I CLCP is set according to three-phase short circuit without delay time. The delay time of the Sec-II CLCP is set as $t_{\text {set }}^{I I}$.

The other part is the risk assessment module of the wind farm. When it is in the risk of large-scale WGs tripping off, this module can make a decision to isolate the fault as soon as possible without delay time.

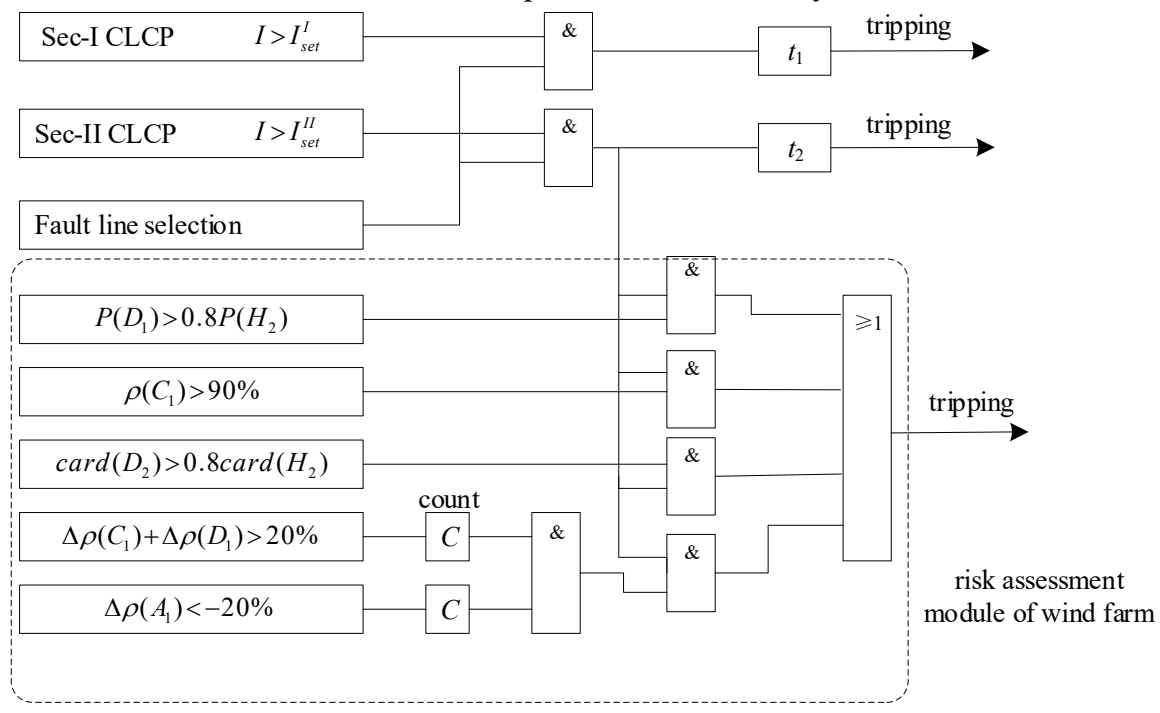

Figure 9. Logic of the improved CLCP scheme

Compared with the traditional CLCP scheme, the biggest difference lies in the addition of the risk assessment module of the wind farm. If the possibility of large-scale WGs tripping off is large, the protective relays drive the circuit breaker tripping immediately. Because the operating status of WGs on non-fault collecting lines is taken into consideration, the probability of these WGs tripping off will decrease. It is hoped to control the tripping off number of WGs, which will increase the controllability and improve safety of wind farm.

\section{Simulation Analysis}

Fig. 10 shows a simulation model of DFIG-based wind farm. To simplify the simulation, six DFIGs are connected to each power collecting line. The labels of DFIGs and wind speeds are marked in fig. 10. Each line is composed of six sections, each length is $1 \mathrm{~km}$, and the line impedance is $(0.105+\mathrm{j} 0.365) \Omega / \mathrm{km}$. The fault time in all simulations is set at $0.1 \mathrm{~s}$. 


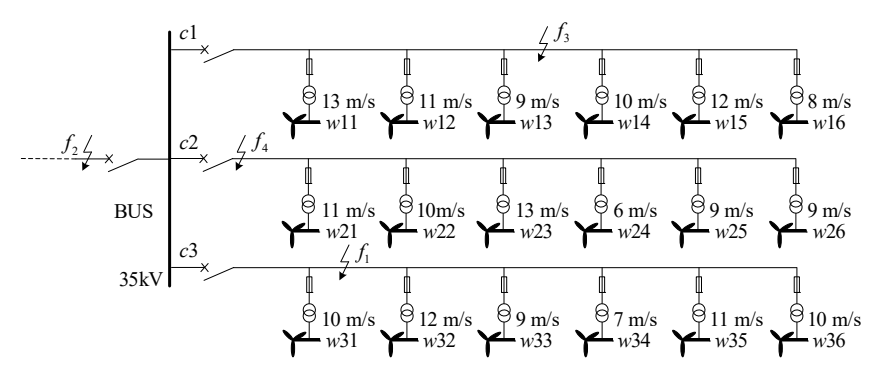

Figure 10. Simulation model of a doubly fed wind farm

System power: the rated capacity is $500 \mathrm{MV} \cdot \mathrm{A}$. $\mathrm{X} / \mathrm{R}$ is 10 . Transformer: the rated capacity is $50 \mathrm{MV} \cdot \mathrm{A}$, and its ratio is $110 \mathrm{kV} / 35 \mathrm{kV}$. The percentage of short-circuit voltage is 10.5 . The transformer impedance is $(0.63+\mathrm{j} 12.91) \Omega$. The tie-line impedance is $(3.06+\mathrm{j} 65.97) \Omega$. The box-type transformer impedance is $(4.08+\mathrm{j} 61.25) \Omega$.

$$
\text { TABLE II }
$$

PARAMETERS OF DFIG

\begin{tabular}{|c|c|c|c|}
\hline Parameter & Value & Parameter & Value \\
\hline Rated power & $1.5 \mathrm{MW}$ & Stator resistance & $0.008 \mathrm{pu}$. \\
\hline Stator rated voltage & $690 \mathrm{~V}$ & Rotor resistance & $0.006 \mathrm{pu}$ \\
\hline Rotor rated voltage & $1975 \mathrm{~V}$ & Stator leakage inductance & $0.172 \mathrm{pu}$. \\
\hline DC voltage & $1150 \mathrm{~V}$ & Rotor leakage inductance & $0.155 \mathrm{pu}$. \\
\hline Rated wind speed & $11 \mathrm{~m} / \mathrm{s}$ & Excitation inductance & $2.9 \mathrm{pu}$. \\
\hline
\end{tabular}

The setting value ( $I_{\text {set }}^{I}$ ) of the Sec-I CLCP is based on the reliability coefficient 1.5 when phase-phase fault occurs at the end of line. The setting value ( $I_{\text {set }}^{I I}$ ) of the Sec-II CLCP is based on 2 times the maximum load current. In addition, the coordination time interval of the second section is $0.5 \mathrm{~s}$. According to the system parameters, we have

$$
\left\{\begin{array}{l}
I_{\text {set }}^{I}=2890 A \\
I_{\text {set }}^{I I}=420 A
\end{array}\right.
$$

Due to the various fault locations and fault types in power transmission lines, and the diversity of low-voltage-ride-through of WGs, it is impossible to simulate all the faults in all aspects. Two typical fault types are simulated for comparison with the traditional CLCP.

Case 1: Three-phase fault at $f_{3}$ on line $\mathrm{c} 3$

It is obvious that the short-circuit current is greater than $I_{\text {set }}^{I}$. However, the CLCP cannot judge whether the fault occurred on the collecting line or the transformer. To ensure selectivity, the coordination time interval of the first section CLCP must be greater than the fuse melting time. The voltage in the wind farm drops drastically during such a serious fault, and the terminal voltage of each WG is at the edge of the low voltage limit. Table III shows the risk indicators of WGs (w11-w16) off-grid on the fault line (c1). The value of risk indicators increases rapidly after fault, the risk indicators of 5 DFIGs at $0.125 \mathrm{~s}$ are over 0.9 and $\operatorname{card}\left(\mathrm{D}_{2}\right)>0.8 \operatorname{card}\left(\mathrm{H}_{2}\right)$. The traditional CLCP do not action until up to the delay time. The improved CLCP will drive the circuit breaker on line c1to trip immediately. It is meaningless to wait for the delay time, because all six DFIGs will be also off-grid at $0.15 \mathrm{~s}$ due to the protective relay actions at the WG-side.

In addition, the external voltage of DFIGs on lines $\mathrm{c} 2$ and $\mathrm{c} 3$ also drops. The risk indicators of these DFIGs at $0.125 \mathrm{~s}$ are less than 0.9 and increase with time. If the fault is isolated in time, it can effectively prevent external voltage dropping and further decrease the risk of large-scale WTs tripping off.

TABLE III

\begin{tabular}{|c|c|c|c|c|c|c|}
\hline Label & $\begin{array}{c}\mathrm{t} / \mathrm{s} \\
0.115\end{array}$ & $\begin{array}{c}\mathrm{t} / \mathrm{s} \\
0.12\end{array}$ & $\begin{array}{c}\mathrm{t} / \mathrm{s} \\
0.125\end{array}$ & $\begin{array}{c}\mathrm{t} / \mathrm{s} \\
0.13\end{array}$ & $\begin{array}{c}\mathrm{t} / \mathrm{s} \\
0.14\end{array}$ & $\begin{array}{c}\mathrm{t} / \mathrm{s} \\
0.14\end{array}$ \\
\hline$w 11$ & 0.311 & 0.747 & 0.896 & 0.953 & 0.975 & 0.980 \\
\hline$w 12$ & 0.510 & 0.884 & 0.955 & 0.983 & 0.992 & 0.995 \\
\hline$w 13$ & 0.684 & 0.950 & 0.990 & 0.996 & 0.999 & 1.000 \\
\hline$w 14$ & 0.862 & 0.981 & 0.992 & 0.996 & 0.997 & 0.998 \\
\hline$w 15$ & 0.727 & 0.955 & 0.984 & 0.995 & 0.997 & 0.997 \\
\hline$w 16$ & 0.725 & 0.954 & 0.984 & 0.995 & 0.997 & 0.997 \\
\hline
\end{tabular}

RISK INDICATORS WHEN THE FAULT IS AT $f_{3}$ ON LINE C3

Case 2: AB phase-phase fault at $f_{4}$ on line c2 with resistance $15 \Omega$ 
Because of the large transition resistance, the voltage in the wind farm maintains a high level during the fault. The short-circuit current of line $\mathrm{c} 2$ is $1810 \mathrm{~A}$, which is lower than the setting value of the Sec-I CLCP. For the traditional CLCP, the fault is not cleared until $0.5 \mathrm{~s}$ by the Sec-II CLCP. However, during this period, part of DFIGs on non-fault collecting lines are in unsafe operation conditions. Table 4 shows the risk indicators of w11-w16 and w31-w36. The risk indicators of w13, w14, w16, w31, w33, w34 and w36 reach 1 at 0.35 s. However, the fault is still not removed. These DFIGs on non-fault lines may be off-grid, which cause large-scale WGs tripping off. The results are shown in table III.

TABLE III

RISK INDICATORS WHEN FAULT IS AT $f_{4}$ ON LINE C2

\begin{tabular}{|c|c|c|c|c|c|c|}
\hline Label & $\begin{array}{c}\mathrm{t} / \mathrm{s} \\
0.15\end{array}$ & $\begin{array}{l}\mathrm{t} / \mathrm{s} \\
0.2\end{array}$ & $\begin{array}{c}\mathrm{t} / \mathrm{s} \\
0.25\end{array}$ & $\begin{array}{l}\mathrm{t} / \mathrm{s} \\
0.3\end{array}$ & $\begin{array}{c}\mathrm{t} / \mathrm{s} \\
0.35\end{array}$ & $\begin{array}{l}\mathrm{t} / \mathrm{s} \\
0.4\end{array}$ \\
\hline$w 11$ & 0.001 & 0.001 & 0.001 & 0.001 & 0.001 & 0.000 \\
\hline$w 12$ & 0.001 & 0.001 & 0.298 & 0.740 & 0.880 & 0.880 \\
\hline$w 13$ & 0.395 & 0.789 & 0.959 & 0.999 & 1.000 & 1.000 \\
\hline$w 14$ & 0.305 & 0.743 & 0.943 & 0.998 & 1.000 & 1.000 \\
\hline$w 15$ & 0.001 & 0.001 & 0.001 & 0.001 & 0.001 & 0.001 \\
\hline$w 16$ & 0.408 & 0.795 & 0.961 & 0.999 & 1.000 & 1.000 \\
\hline w31 & 0.373 & 0.778 & 0.955 & 0.999 & 1.000 & 1.000 \\
\hline$w 32$ & 0.001 & 0.001 & 0.176 & 0.675 & 0.882 & 0.882 \\
\hline w33 & 0.396 & 0.789 & 0.959 & 0.999 & 1.000 & 1.000 \\
\hline w34 & 0.420 & 0.801 & 0.963 & 0.999 & 1.000 & 1.000 \\
\hline$w 35$ & 0.001 & 0.001 & 0.001 & 0.001 & 0.001 & 0.001 \\
\hline$w 36$ & 0.305 & 0.743 & 0.943 & 0.998 & 1.000 & 1.000 \\
\hline
\end{tabular}
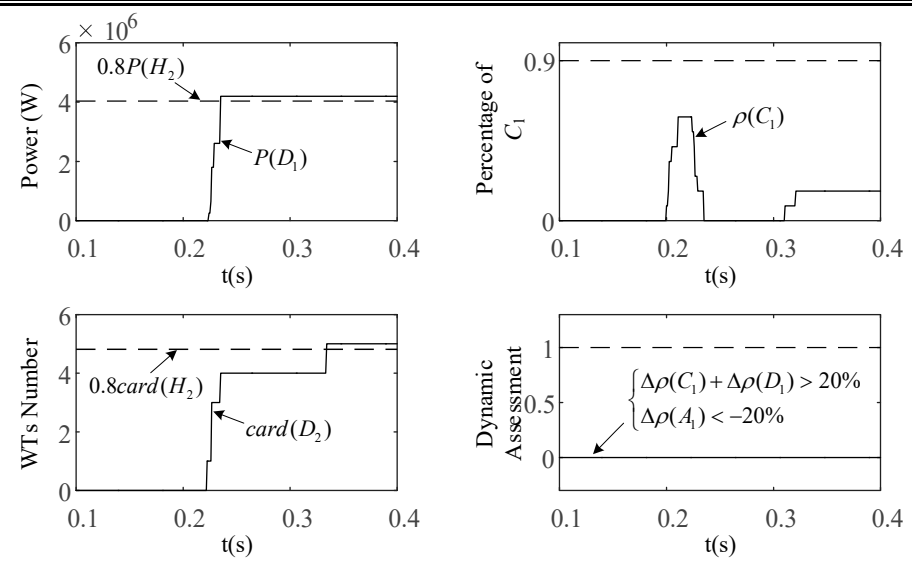

Figure 11 Risk assessment results of the wind farm

If introducing the risk assessment module, we can avoid the weakening speed of the CLCPs. In the dynamic assessment, $\Delta t=0.1 \mathrm{~s}, P\left(D_{1}\right)$ reaches the setting value at $0.23 \mathrm{~s}$, and $\operatorname{card}\left(D_{2}\right)$ reaches the setting value at $0.33 \mathrm{~s}$. As is shown, before DFIGs on non-fault lines go off-grid, the risk assessment module has given advices to drive the circuit breaker to trip in order to clear the fault. In this condition, the protective relay of the CLCP issues a command to trip line $\mathrm{c} 2$ at $0.23 \mathrm{~s}$. The results are shown in table IV.

TABLE IV

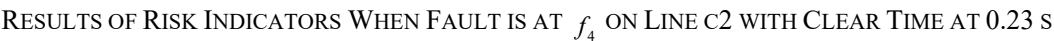

\begin{tabular}{|c|c|c|c|c|c|c|}
\hline Label & $\begin{array}{c}\mathrm{t} / \mathrm{s} \\
0.15\end{array}$ & $\begin{array}{l}\mathrm{t} / \mathrm{s} \\
0.2\end{array}$ & $\begin{array}{c}\mathrm{t} / \mathrm{s} \\
0.25\end{array}$ & $\begin{array}{l}\mathrm{t} / \mathrm{s} \\
0.3\end{array}$ & $\begin{array}{c}\mathrm{t} / \mathrm{s} \\
0.35\end{array}$ & $\begin{array}{l}\mathrm{t} / \mathrm{s} \\
0.4\end{array}$ \\
\hline w11 & 0.001 & 0.001 & 0.001 & 0.001 & 0.001 & 0.000 \\
\hline w12 & 0.001 & 0.001 & 0.001 & 0.001 & 0.001 & 0.004 \\
\hline w13 & 0.395 & 0.789 & 0.001 & 0.000 & 0.000 & 0.000 \\
\hline w14 & 0.305 & 0.743 & 0.001 & 0.001 & 0.000 & 0.001 \\
\hline w15 & 0.001 & 0.001 & 0.001 & 0.001 & 0.000 & 0.000 \\
\hline w16 & 0.408 & 0.795 & 0.001 & 0.000 & 0.003 & 0.003 \\
\hline w31 & 0.373 & 0.778 & 0.001 & 0.001 & 0.000 & 0.001 \\
\hline w32 & 0.001 & 0.001 & 0.001 & 0.001 & 0.001 & 0.001 \\
\hline w33 & 0.396 & 0.789 & 0.001 & 0.000 & 0.000 & 0.001 \\
\hline w34 & 0.420 & 0.801 & 0.000 & 0.001 & 0.001 & 0.000 \\
\hline w35 & 0.001 & 0.001 & 0.001 & 0.001 & 0.000 & 0.000 \\
\hline w36 & 0.305 & 0.743 & 0.001 & 0.001 & 0.000 & 0.000 \\
\hline
\end{tabular}

The simulations show that the coordination time of traditional CLCP may cause large-scale WGs tripping off. Instead of considering the fault location and fault types, the improved CLCP considers the behavior of WGs in the wind farm during the fault. Real-time risk indicators of WGs are used to guide the protective relays. The more serious the fault is, the more quickly 
the fault is cleared. If the fault is not very serious, the improved CLCP can also ensure selectivity until the risk indicators of WGs reach the setting value.

\section{Conclusion}

Selectivity and sensitivity are the main issues for traditional CLCP, which makes it difficult to clear the faults reliably and quickly. The coordination time interval weakens the protection speed and may easily cause large-scales WGs tripping off. The improved CLCP scheme is proposed in this paper. Preventing large-scale WGs tripping off during the fault is studied. Improving the safety of the entire wind farm is the goal. The CLCP is improved through on-line risk assessment of WGs in wind farm. The main conclusions are as follows.

The traditional CLCP is analyzed in detail. The discoordination and the weaken speed of the CLCP in wind farm is reveled. We increase the setting value and decrease the protection zone of the first section CLCP so that we can reduce the delay time, which helps the CLCP speed better. For the outside of protection zone, the second one is to protect the rest of the collecting line.

Considering the fault ride through ability of WGs, we calculate the risk of WGs during the fault in order to guide the CLCP. Risk Indicators are used to describe the probability of WGs going off-grid during fault. According to the different causes of WGs going off grid, different functions are created to fit the relationship between WG safety margin and the risk indicator. The risk assessment of wind farms based on classification analysis of risk indicators is proposed. To extract the key information from the numerous risk indicators, we evaluated the possibility of WG going off-grid from static and dynamic aspects.

An improved CLCP scheme is proposed. Different from the traditional current protection, the scheme introduces the risk assessment component of wind farm to accelerate protection. The proposed scheme improves the safety of WGs in wind farm and improves the speed of the CLCP, which is helpful to prevent large-scale WTs tripping off.

Author Contributions: Author (1) Wei Jin designed the main idea and methods of the paper. Author (2) Yuping Lu implemented the methods of the paper. Author (3) Chao Yu added included extra simulations according to the opinions of the reviewers.

Acknowledgments: This work was supported by the National Natural Science Foundation of China under Grant 51677026 and 51377022 .

Conflicts of Interest: The authors declare no conflict of interest.

\section{References}

[1] M. Yousefvand, T. Han, N. Ansari, et al., "Distributed energy-spectrum trading in green cognitive radio cellular networks," IEEE Transactions on Green Communications and Networking, vol. 1, no. 3, pp. 253-263, Apr. 2017.

[2] S.K Ma, H. Geng, L. Liu, et al., "Grid-synchronization stability improvement of large scale wind farm during severe grid fault," IEEE Transactions on Power Systems, vol. 33, no. 1, pp. 216 - 226, May 2017.

[3] C.S. Hu, J. Gong, X.L. Wang, et al., "Optimal green energy utilization in MIMO systems with hybrid energy supplies," IEEE Transactions on Vehicular Technology, vol. 64, no. 8, pp. 3675 - 3688, Sep. 2014.

[4] L. Gan, G.Y. Li, M. Zhou, "Coordinated planning of large-scale wind farm integration system and transmission network," CSEE Journal of Power and Energy Systems, vol. 2, no. 1, pp. 19 - 29, Mar. 2016.

[5] T.S. Bi, Y.B. Li, L.H. Ma, et al., "Configuration and setting of relay protection for wind farm and its outgoing line," Power System Protection and Control, vol. 42, no. 5, pp. 45-50. Feb. 2014.

[6] M. Kheshti, X.N. Kan, G.B Song, et al., "Modeling and fault analysis of doubly fed induction generators for gansu wind farm application," Canadian Journal of Electrical and Computer Engineering, vol. 38, no. 1, pp. 52 - 64, Dec. 2015.

[7] Q. Che, Y.P. Lu, "Research on wind farm relay protection value setting based on crowbar circuit LVRT technology," Power System Protection and Control, vol. 41, no. 2, pp. 97-102. Jan. 2013.

[8] N. Tong, X.N. Lin, Z.T. Li, et al., "Study for reciprocal effect between overcurrent protection and doubly-fed induction generator feeding current under the condition of symmetrical voltage sag," Proceedings of the CSEE, vol. 34, no. 22, pp. 3806-3814. Aug. 2014.

[9] H. Yang, Z. Zhang; X.G. Yin, et al., "Study of the Collecting-line-current-protection setting in centralized accessed double-fed wind farms, 2016 IEEE Power and Energy Society General Meeting (PESGM), Boston, MA, USA, 2016.

[10] S. A. Saleh, E. Ozkop, A.S. Aljankawey, "The Development of a coordinated anti-islanding protection for Collecting systems with multiple distributed generation units," IEEE Transactions on Industry Applications, vol. 52, no. 6, pp. 4656 - 4667, Jul. 2016.

[11] K. Schönleber, E. Prieto-Araujo, S. Ratés-Palau, et al., "Extended current limitation for unbalanced faults in MMC-HVDC-connected wind power plants," IEEE Transactions on Power Delivery, vol. PP, no. 99, pp. 1-1, Dec. 2017.

[12] D. Jones, K. Bennett, "Wind farm Collecting protection using directional overcurrent elements," IEEE PES Transmission and Distribution Conference and Expositon. Orlando, USA, 2012.

[13] F.F. Chen, Q. Zhao, J.B. Lan, et al., "Synchronous sampling and differential protection of Collecting lines in wind farm," Automation of electric power system, vol. 37, no. 14, pp. 19-24. Jul. 2013.

[14] D. K. Singh, A. K. Singh, S. R. Mohanty, "Wind power generation by PMSG and fault protection using over-current and differential frequency relay," 2016 IEEE Region 10 Humanitarian Technology Conference (R10-HTC), Agra, India, 2017.

[15] N. Safari, C. Y. Chung; G. C. D. Price, "Novel multi-step short-term wind power prediction framework based on chaotic time series analysis and singular spectrum analysis," IEEE Transactions on Power Systems, vol.33, no. 1, pp. 590 - 601, Apr. 2018. 
[16] M. Y. Zargar, M. U. Mufti, S. A. Lone, "Adaptive predictive control of a small capacity SMES unit for improved frequency control of a wind-diesel power system," IET Renewable Power Generation, vol. 11, no. 14,pp. 1832 - 1840, Dec. 2017.

[17] P. F. Gonçalve, S. M. Cruz, M. B. Abadi, et al., "Fault-tolerant predictive power control of a DFIG for wind energy applications," IET Electric Power Applications, vo.11, no. 6, pp. 969 - 980, Jul. 2017.

[18] A. Rabiee, A. Soroudi, A. Keane, "Risk-averse preventive voltage control of AC/DC power systems including wind power generation," IEEE Transactions on Sustainable Energy, vol. 6, no. 4, pp. 1494 - 1505, Ju. 2015.

[19] M. H. Mehdiabadi, J. Zhang, K. W. Hedman, "Wind power dispatch margin for flexible energy and reserve scheduling with increased wind generation," IEEE Transactions on Sustainable Energy, vol. 6, no. 4, pp. 1543-1552, Aug. 2015.

[20] C. Wang, F. Liu, J. Wang, et al., "Risk-based admissibility assessment of wind generation integrated into a bulk power system," IEEE Transactions on Sustainable Energy, vol. 7, no. 1, pp. 325 - 336, Nov. 2015.

[21] P. Liu, Z. T. Li, Y. X. Zhuo, et al., "Design of wind turbine dynamic trip-off risk alarming mechanism for large-scale wind farms," IEEE Transactions on Sustainable Energy, vol. 8, no. 4, pp.1668 - 1678, May 2017.

[22] Y.F. Pan, S.W. Mei; F. Liu, et al., "Admissible Region of Large-Scale Uncertain Wind Generation Considering Small-Signal Stability of Power Systems," IEEE Transactions on Sustainable Energy, vol. 7, no. 4, pp. 1611 - 1623, May 2016.

[23] J. Kim, E. Muljad, J. Park, et al., "Adaptive Hierarchical Voltage Control of a DFIG-Based Wind Power Plant for a Grid Fault," IEEE Transactions on Smart Grid, vol. 7, no. 6, pp. 2980 - 2990, May 2016.

[24] T. Niu, Q. L. Guo; H. B. Sun, et al., "Voltage security regions considering wind power curtailment to prevent cascading trip faults in wind power integration areas," IET Renewable Power Generation, vol. 11, no. 1, pp. 54-62, Apr. 2017.

[25] P. Liu, Z. T. Li, Y. X. Zhuo, et al., "Design of wind turbine dynamic trip-off risk alarming mechanism for large-scale wind farms," IEEE Transactions on Sustainable Energy, vol. 8, no. 4, pp. 1668 - 1678, May 2017.

[26] Y. Kun, X. J. Lin, N. Tong, et al., "A hyperbolic tangent function operation characteristic based inverse-time protection method of wind farm collector line," Proceedings of the CSEE, vol. 38, no. 0, pp. 1 -12, Apr. 2018. 